American Journal of Biochemistry and Biotechnology, 2012, 8 (2), 63-70

ISSN: 1553-3468

(C) 2012 S.K. Srivastava et al., This open access article is distributed under a Creative Commons Attribution

(CC-BY) 3.0 license

doi:10.3844/ajbb.2012.63.70 Published Online 8 (2) 2012 (http://www.thescipub.com/ajbb.toc)

\title{
Micrornas are Not That Small to Ignore
}

\author{
${ }^{1}$ Sanjeev Kumar Srivastava, ${ }^{2}$ Sonal Somvanshi and ${ }^{2}$ Vivek Pratap Singh \\ ${ }^{1}$ Department of Oncologic Sciences, Mitchell Cancer Institute, Mobile, AL, 36604, \\ ${ }^{2}$ Department of Pharmacology and Cell Biophysics, University of Cincinnati, College of Medicine, Cincinnati, Ohio
}

Received 2012-04-14; Revised 2012-05-7; Accepted 2012-05-20

\begin{abstract}
MicroRNAs (miRNAs) are small, noncoding RNA molecule that negatively regulates gene expression by causing either degradation or translational inhibition of their target mRNAs. These miRNAs are key regulators of various biological processes such as differentiation, maturation and maintenance of immune homeostasis. Furthermore, deregulated expression of miRNA has now been shown to regulate several disease processes by regulating tumorigenesis, angiogenesis, apoptosis and metastasis in cancer and other diseases such as rheumatoid arthritis, diabetes and cardiovascular diseases. This review article summarizes the present status of miRNA research, with major emphasis on the roles of miRNAs in the development of various human diseases.
\end{abstract}

Keywords: MicroRNA, diabetes, cardiovascular disease, cancer

\section{INTRODUCTION}

MicroRNAs (miRNAs) are small non-coding RNAs $(\sim 22 \mathrm{nt})$, which are involved in the regulation of gene expression. These miRNAs negatively regulates gene expression at the posttranscriptional level by binding to the 3'UTR of target mRNAs through base pairing, resulting in either target mRNAs cleavage or causing translation inhibition (Ambros et al., 2004; Bartel, 2004). According to recent studies, in humans, more than 500 miRNAs have been identified and it is predicted that the total number may exceed up to 1000 (Bentwich et al., 2005; Griffiths-Jones et al., 2008). Despite the large number of identifying miRNAs, the target mRNAs and the biological function have been attributed to only a few of them (Bhardwaj et al., 2010). Growing evidences suggest that miRNAs play significant roles in several biological processes like differentiation, cell proliferation, embryonic development, cell proliferation and apoptosis (Esquela-Kerscher and Slack, 2006). With the continuous influx of studies on miRNAs, it is now becoming evident that these miRNAs exhibit differential expression in several human diseases, including cancer (Calin and Croce, 2006; Esquela-Kerscher and Slack, 2006) and play important roles in the development of other disease processes such as cardiovascular disease
(Latronico et al., 2007), schizophrenia (Hansen et al., 2007; Perkins, 2007), renal function disorders (Amrouche et al., 2011), fragile-X mental retardation syndrome (Provost, 2010), diabetes (Dehwah et al., 2012), hepatitis (Murakami et al., 2010) and obesity (Dehwah et al., 2012). Considering the growing number of studies relating miRNAs and various diseases this review article will focus more on newly identified miRNAs in disease (Table 1) and will discuss about their role and its significance in diagnostics and prognostics. Furthermore, this study will provide a deeper insight about the role of recently identified miRNAs.

\section{1. miRNAs in Cancer}

Cancer is considered as one of the major health problem worldwide (Jemal et al., 2011). According to an estimate, one in 4 deaths in the United States occurs because of cancer. Development of cancer occurs when normal cells in the body start developing in an abnormal growth fashion. In most of the cancers, genes responsible for maintaining growth gets apparently expressed or activated, thus causing uncontrolled growth of the cancer cells. During the past few years, expression signatures of miRNAs in many human cancers have been identified (Calin and Croce, 2006) and several lines of incidences suggest that these miRNAs play significant role in the 
development and progression of cancer (Sotiropoulou et al., 2009). Growing studies also reveal that the aberrant expression of miRNAs is associated with the stage and metastasis of cancers (Shimono et al., 2009). These miRNA may function as either tumor promoters (oncomirs) or tumor suppressors (anti-oncomirs) (Bhardwaj et al., 2010). Thus, miRNAs may play important roles in cancer development, progression, prognosis and diagnosis. The expression profile of miRNA in multiple cancer types Including Chronic Lymphocytic Leukemia (CLL) (Moussay et al., 2011), breast (Schooneveld et al., 2012), colon (Piepoli et al., 2012), lung (Wang et al., 2012), pancreatic (Srivastava et al., 2011), prostate (Hassan et al., 2012), cancers and glioblastomas (D'Urso et al., 2012), reveal that a large number of miRNAs are aberrantly expressed in various cancers. In CLL, expression of miRNAs, miR-15a and miR-16 was downregulated (Hanlon et al., 2009). Bcl2, an anti-apoptotic protein is expressed at very high levels in CLL and is considered as an important survival factor of the cancer cells. Down regulated expression of miR15a and miR-16-1 maintains the enhanced levels of BCL-2 and thus confers apoptosis resistance in CLL (Cimmino et al., 2005). In another study, miR-16 is shown to suppress the growth of prostate cancer cells by regulating the expression of CDK1 and CDK2, which are associated with cell cycle control and proliferation (Takeshita et al., 2010). Another study on miRNA in Lymphoma has shown that miR-17-92 cluster is upregulated in lymphomas. Their study demonstrated that the miR-17-92 cluster can enhance tumorigenesis by inhibiting apoptosis (Croce, 2008). Furthermore, several studies also show that this cluster is overexpressed in a wide array of cancers including breast, colon, lung, prostate and pancreatic endocrine. Among others oncogenic miRNAs, miR-21 has been shown to promote apoptosis through activation of caspases in human glioblastoma cells (Chan et al., 2005). In breast cancer cells, silencing of miR-21 inhibited cell growth in vitro and in vivo by causing downregulation of $\mathrm{Bcl}-2$ and induction of apoptosis (Si et al., 2007). MiR-155 is overexpressed in many cancers including B-cell lymphomas, Burkitt lymphoma, Hodgkin's lymphoma and breast, lung, colon and thyroid cancers. Its expression was significantly correlated with poor survival in pancreatic cancer patients (Greither et al., 2010). A study performed on mice also identified that mice overexpressing miR-155 are able to develop B-cell malignancy (Costinean et al., 2009). A recent study conducted by Srivastava et al. (2011) and coworkers identified a tumor suppressor miRNA in pancreatic cancer. Their study demonstrated that miR-150 exerts its tumor suppressor function by directly targeting an oncoprotein MUC4 (Srivastava et al., 2011). In lung and colon cancer cells Let-7 family members of miRNAs are downregulated and that correlates with the shortened postoperative survival in lung cancer patients (Takamizawa et al., 2004). Studies on miR-125a and miR-125b suggest that their expression is either downregulated or lost in breast cancer (Scott et al., 2007). These miRNAs exert their function by regulating the oncogenes ERBB2 and ERBB3. Furthermore, miR143 and miR-145 are frequently downregulated in colorectal and breast cancers as well as B-cell malignancies suggesting their involvement in cancer (Luo et al., 2011; Akao et al., 2007). With the huge influx of data, it cannot be overruled that there may be many other miRNAs which are involved in cancers development and progression that need to be explored.

\section{2. miRNAs in Cardiovascular Diseases}

Cardiovascular diseases are the major cause of mortality in developed countries. Therefore extensive studies have been done to develop novel diagnostic and therapeutic strategies to fight with the devastating outcome of these diseases. Several recent investigations suggest that miRNAs regulate various processes including angiogenesis, cardiogenesis, endothelial and myocyte growth, contractility and cardiac rhythm (Latronico et al., 2007; Elton et al., 2011; Care et al., 2007) and studies also indicate involvement of these miRNAs in the pathogenesis of various cardiovascular diseases. Therefore, miRNAs have been considered as a potential target for therapeutic intervention. The expression of specific miRNAs is altered in diseased hearts and vessels as well as in stroke (Bonauer et al., 2009; Rink and Khanna, 2010) and experiments of gain- and loss-of-function in mice have shown that miRNAs regulates multiple forms of cardiovascular disease (Care et al., 2007; Rooij and Olson, 2007). In cardiac hypertrophic condition some miRNAs are downregulated, their forced expressions prevents cardiac myocyte hypertrophy. Furthermore, miR-21 which is an overexpressed miRNA in hypertrophic animal and human hearts, repression of this miRNA inhibits hypertrophic hearts in vitro (Cheng and Zhang, 2010). A study on rats has shown that inhibiting miR-21 exerts negative effect on the neointimal lesion formation in rat artery after angioplasty, thus suggesting the importance of miRNAs as regulators in the development of proliferative vascular diseases. The possible implication of miRNAs in the cardiovascular system is also supported by the findings that depletion of the miRNA-processing enzyme Dicer causes defects in angiogenesis, vessel formation and cardiac development (Kuehbacher et al., 2007; Suarez et al., 2007; 2008). 
Table 1. List of MicroRNAs and their expression associated with various diseases

\begin{tabular}{|c|c|c|c|}
\hline miRNA & Diseases & Expression & Reference \\
\hline miR-15a and miR-16-1 & CLL & Downregulated & (Hanlon et al., 2009) \\
\hline miR-17-92 & Lymphomas & Upregulated & (Croce, 2008) \\
\hline $\operatorname{miR}-21$ & Breast cancer & Upregulated & (Si et al., 2007) \\
\hline $\operatorname{miR}-150$ & Pancreatic cancer & Downregulated & (Srivastava et al., 2011) \\
\hline $\operatorname{miR}-21$ & Hypertrophy & Upregulated & (Cheng and Zhang, 2010) \\
\hline miR-1 & Ischemic heart, Arrhythmogenesis & Upregulated & (Tang et al., 2009) \\
\hline $\begin{array}{l}\text { miR-34a, miR-200a and } \\
\text { miR-520, let-7f, miR-371 } \\
\text { and miR-517/517 }\end{array}$ & Alzheimer's disease & Upregulated & (Maes et al., 2009) \\
\hline $\begin{array}{l}\text { miR-144, miR-146a, miR-150 } \\
\text { and miR-182 }\end{array}$ & $\begin{array}{l}\text { Impaired fasting glucose } \\
\text { and Type } 2 \text { Diabetes }\end{array}$ & Upregulated & (Karolina et al., 2011) \\
\hline $\operatorname{miR}-25$ & Diabetic nepropathy & Downregulated & (Fu et al., 2010) \\
\hline $\begin{array}{l}\text { miR-146a, miR-155, } \\
\text { miR-132 and miR-16 }\end{array}$ & & Upregulated & (Pauley et al., 2008) \\
\hline miR-124a and miR-15a & Rheumatoid arthritis & Downregulated & (Wittmann and Jack, 2011) \\
\hline $\begin{array}{l}\text { miR-16, miR-21, miR-23a, } \\
\text { miR-24, miR-29a, miR-126, } \\
\text { miR-195 and let-7f }\end{array}$ & ulcerative colitis & Upregulated & (Dalal and Kwon, 2010) \\
\hline miR-19b and miR- 629 & Crohn's colitis & Downregulated & (Wu et al., 2010) \\
\hline miR-146a & Systemic lupus erythematosus/lupus & Downregulated & (Ceribelli et al., 2011) \\
\hline
\end{tabular}

In a rat model of myocardial infarction and in human hearts with coronary heart disease, miR-1 was significantly unregulated in ischemic heart tissue (Tang et al., 2009; Brattelid et al., 2011). Several studies have shown the significance of miRNAs in cardiac function and maintaining its structure. MiR-1, miR-133, miR-208, miR-21 and miR- 221/222 are associated with cardiac growth, erythropoiesis, angiogenesis, proliferation (Latronico et al., 2007; Bauersachs et al., 2007). Overexpression of mature miR-1 increases the severity of arrhythmogenesis and its downregulation suppress arrhythmias (Tang et al., 2009; Brattelid et al., 2011; Latronico et al., 2007; Latronico and Condorelli, 2009). All these evidences thus support the potential of miRNAs in the development of cardiovascular diseases.

\section{3. miRNAs in Neurodegenerative Diseases}

Neurodegenerative Diseases (NDs) are the diseases which result from many genetic and environmental factors. Several lines of evidence suggests the role of miRNAs in causing neurodegeneration or neuroprotection. In the current situation, with the emergence of miRNAs it is now considered that miRNAs play significant role in several mammalian brain-related biochemical pathways, including neuroplasticity and stress responses and contributes to various neurological disorders in humans, like fragile $\mathrm{X}$ syndrome (Caudy et al., 2002), Alzheimer's Disease (AD) (Hebert et al., 2010). The correlation between aberrant expression of miRNA and neurological diseases can be best explained with the fragile $\mathrm{X}$ disease. In patients suffering from this disease, there is loss of Fragile X Mental Retardation 1 Protein (FMRP) and that impairs Dicer and RISC functions which are required for miRNA-mediated synaptic plasticity and dendritic development (Maes et al., 2009). There are other experimental evidences which also suggest that if miRNA processing is altered by inactivating Dicer in Drosophila that also prevents dendritic development (Maes et al., 2009) and enhances polyglutamine and tau-induced neurodegeneration (Hebert et al., 2010). Loss of midbrain Dopaminergic Neurons (DNs) which is a Parkinson's disease-like phenotype, was observed in conditional Dicer knockout mice in post-mitotic midbrain, which suggested that miRNAs are essential for the terminal differentiation and/or maintenance of multiple neuron types, including midbrain DNs (Kim et al., 2007). In a separate study miRNA profiling on AD affected brain and PBMC was performed and a specific signature was identified. Upregulated expression of $\mathrm{miR}-34 \mathrm{a}$, miR-200a and miR520, let-7f, miR-371 and miR-517/517* was observed in the CSF and PBMC of AD patients. Of note, miR$520 \mathrm{~h}$ is reported to be highly up-regulated in AD brain (Maes et al., 2009) and its elevated expression in PBMCs of AD suggests that these miRNAs may play an important role in the systemic manifestations of the disease. 


\section{4. miRNAs in Diabetes}

Diabetes is an autoimmune disorder and is often genetically inherited. So far more than 19 InsulinDependent Diabetes Mellitus (IDDM) susceptibility loci have been identified in humans. MiRNAs are linked to the regulation of different biological pathways associated and are now widely implicated with the diabetes. In a study, more than 27 miRNAs were observed to be located on 9 human IDDM loci and it was also revealed that some of the miRNAs may target autoimmune- and $\beta$-cell-related genes (Zhou et al., 2008). In the diabetic rat model, an altered profile of miRNA expression in insulin target tissues was observed. A growing body of data suggests significant roles of miRNAs in insulin production, secretion and in glucose homeostasis and adipocyte differentiation. Karolina et al. (2011), performed an miRNA expression profiling in pancreas, liver, adipose and skeletal muscle and in blood samples from the T2D rat model as well as from Impaired Fasting Glucose (IFG) and T2D male patients and their investigation revealed that four miRNAs i.e. miR-144, miR-146a, miR-150 and miR-182 to be a potential signature miRNAs that distinguished IFG and T2D (Karolina et al., 2011). According to published studies, role of several miRNAs like miR-124a2, miR-195, miR$15 \mathrm{a}$, miR-15b and miR-16 have been identified in regulating pancreatic development (Baroukh et al., 2007; Joglekar et al., 2007). Up-regulation or downmodulation of miR-124a2 can cause either elevated or decreased insulin mRNA levels, respectively (Baroukh et al., 2007). Notably, overexpression of miR-124a in MIN6 cell line was able to decrease glucose-stimulated insulin secretion (Lovis et al., 2008). Krek et al. (2005) have shown that miR-375 and miR-124 may share common pathways in the regulation of insulin secretion (Krek et al., 2005). Furthermore, overexpression of miR410 elevates the level of glucose-stimulated insulin secretion in MIN6 cells (Hennessy et al., 2010). MiR-7 and miR-9 have also been identified as important regulators of insulin secretion (Bravo-Egana et al., 2008). The expression of miR-21, miR-34a and miR146a was increased in the islets of non-obese diabetic mice during development of pre-diabetic insulitis (Roggli et al., 2010). Additionally, miR-126 was identified to be involved in the development of insulin resistance induced by mitochondrial dysfunction (Ryu et al., 2011). In diabetic nephropathy, reduced level of miR-25 was seen in the kidney from both diabetic rats and high glucose-treated mesangial cells which indicate that miR-25 may regulate NOX4 expression and function in diabetic nepropathy (Fu et al., 2010).

\section{5. miRNAs in Rheumatoid Arthritis}

Rheumatoid Arthritis (RA) is a common systemic inflammatory disease. The disease is characterized by inflammation of synovial tissue, progressive cartilage destruction and bone erosion of affected joints (Srivastava et al., 2011). RA is a major cause of disability and is even correlated with increased mortality in severe cases. It is now known that miRNAs are involved in the modulation of inflammatory process in the joints. Several studies demonstrate that in Peripheral Blood Mononuclear Cells (PBMC) of RA high levels of miR-146a, miR-155, miR-132 and miR-16, were observed (Pauley et al., 2008). In a separate, study elevated expression of miR-146a in different cells and tissues of RA patients was observed, that suggest its association with the disease severity (Nakasa et al., 2011). Also, miR-146a expression in RA positively correlated with the levels of TNF- $\alpha$ in both Peripheral Blood (PB) and Synovial Fluid (SF) (Nakasa et al., 2011). Some groups have also provided their input and their data shows that miR-155 and miR-146a are upregulated, while miR-124a and miR-15a are downregulated miRNAs in the synovial membrane in RA (Wittmann and Jack, 2011). It was identified and reported that miR-124a regulates the cell cycle (Kawano and Nakamachi, 2011) and miR-155 regulates the metalloproteinases production (Leng et al., 2011) of RA synovial fibroblasts. Furthermore overexpression of miR-15a expression induces apoptosis in these cells (Nagata et al., 2009).

\section{6. miRNAs in Inflammatory Bowel Disease}

Crohn's Disease (CD) and Ulcerative Colitis (UC) are the two different types of idiopathic Inflammatory Bowel Disease (IBD) (Odze, 2003). This disease is the outcome of an altered immune response to environmental factors in genetically susceptible individuals and the aberrant gene and protein expression signatures. In a study on samples from colon biopsy miRNA microarray profiles was performed and their analysis revealed a distinct miRNA signature. Three miRNAs viz miR-192, miR-375 and miR-422b were downregulated in the UC tissues, whereas eight miRNAs viz miR-16, miR-21, miR-23a, miR-24, miR-29a, miR126, miR-195 and let-7f were significantly increased in active UC tissues (Dalal and Kwon, 2010). Profiling 
done on samples of colon biopsies of 5 patients with chronically active $\mathrm{CD}$ and 13 control individuals revealed upregulated expression of miR-23b, miR-106 and miR-191 in tissues from patients with active CD, while miR-19b and miR- 629 were downregulated in Crohn's colitis patients (Wu et al., 2010). Studies also demonstrate that miRNA expression profiles correlates with the disease progression.

\section{7. miRNAs in Systemic Lupus Erythematosus/Lupus}

Systemic Lupus Erythematosus (SLE) is a chronic disease that causes inflammation, pain and swelling. Sometimes it is also called as "great imitator" because it can affect the skin, joints, kidneys, lungs, nervous system and other organs of the body. In SLE patients, expression of miR-146a expression is downregulated in PBMCs as compared to healthy controls. This decrease in miR-146a was associated with disease severity (Ceribelli et al., 2011). Working on the line to get the more insight about involvement of miRNAs, an miRNA profiles in SLE patients, Idiopathic Thrombocytopenic Purpura (ITP) patients and healthy controls was performed that identified a group of 13 miRNAs exhibiting same expression pattern in SLE and ITP whereas, miR-184, miR-198 and miR-21 were observed to have a differential expression in SLE compared to controls (Dalal and Kwon, 2010). In case of ITP, Six miRNAs were downregulated but this downregulation was not observed in patients with SLE. In kidney biopsies taken from lupus nephritis patients, miRNAs are differentially expressed compared to controls ( $\mathrm{Te}$ et al., 2010).

\subsection{Conclusion and Perspective}

Growing evidences suggest that miRNAs play important role in a various developmental process including cell proliferation, cell cycle, cell differentiation, metabolism, apoptosis, developmental timing. These miRNAs are either down-regulated or overexpressed in various organs including lung, liver and kidney and exert diverse functions. Several studies have experimentally proved the links between miRNA and various disease conditions including cancer, cardiovascular diseases, arthritis, diabetes, Lupus. Additionally, identification of miRNAs in specific disease could provide impetus for the disease diagnosis, prognosis and evaluation of treatment response. Furthermore, targeting miRNAs may be a novel therapeutic approach in human diseases.

\section{REFERENCES}

Akao, Y., Y. Nakagawa, Y. Kitade, T. Kinoshita and T. Naoe et al., 2007. Downregulation of microRNAs143 and -145 in B-cell malignancies. Cancer Sci., 98: 1914-1920. DOI: 10.1111/j. 1349-7006.2007.00618. x

Ambros, V., 2004. The functions of animal microRNAs. Nature, 431: 350-355. DOI: 10.1038/nature02871

Amrouche, L., R. Bonifay and D. Anglicheau, 2011. MicroRNAs in pathophysiology of renal disease: An increasing interest. Med. Sci., 27: 398-404. DOI: 10.1051/medsci/2011274016

Baroukh, N., M.A. Ravier, M.K. Loder, E.V. Hill and A. Bounacer et al., 2007. MicroRNA-124a regulates foxa2 expression and intracellular signaling in pancreatic $\beta$-cell lines. J. Biol. Chem., 282: 1957519588. DOI: $10.1074 / \mathrm{jbc} . M 611841200$

Bartel, D.P., 2004. MicroRNAs: Genomics, biogenesis, mechanism and function. Cell., 116: 281-297. PMID: 14744438

Bauersachs, J. and T. Thum, 2007. MicroRNAs in the broken heart. Eur. J. Clin. Invest., 37: 829-833. DOI: $10.1111 /$ j.1365-2362.2007.01878.x

Bentwich, I., A. Avniel, Y. Karo, R. Aharonov and S. Gilad et al., 2005. Identification of hundreds of conserved and nonconserved human microRNAs. Nat Genet., 37: 766-770. DOI: 10.1038/ng1590

Bhardwaj, A., S. Singh and A.P. Singh, 2010. MicroRNA-based Cancer Therapeutics: Big Hope from Small RNAs. Mol. Cell Pharmacol., 2: 213219. DOI: $10.4255 / \mathrm{mcpharmacol} .10 .27$

Bonauer, A., G. Carmona, M. Iwasaki, M. Mione and M. Koyanagi et al., 2009. MicroRNA-92a controls angiogenesis and functional recovery of ischemic tissues in mice. Science, 324: 1710-1713. DOI: $10.1126 /$ science. 1174381

Brattelid, T., E.K. Aarnes, E. Helgeland, S. Guvaag and H. Eichele et al., 2011. Normalization strategy is critical for the outcome of miRNA expression analyses in the rat heart. Physiol. Genomics., 43: 604-610. DOI: 10.1152/physiolgenomics.00131.2010

Bravo-Egana, V., S. Rosero, R.D. Molano, A. Pileggi and C. Ricordi et al., 2008. Quantitative differential expression analysis reveals miR-7 as major islet microRNA. Biochem. Biophys. Res. Commun., 366: 922-926. DOI: 10.1016/j.bbrc.2007.12.052

Calin, G.A. and C.M. Croce, 2006. MicroRNA signatures in human cancers. Nat. Rev. Cancer., 6: 857-866. DOI: $10.1038 / \mathrm{nrc} 1997$ 
Care, A., D. Catalucci, F. Felicetti, D. Bonci and A. Addario et al., 2007. MicroRNA-133 controls cardiac hypertrophy. Nat Med., 13: 613-618. DOI: $10.1038 / \mathrm{nm} 1582$

Caudy, A.A., M. Myers, G.J. Hannon and S.M. Hammond, 2002. Fragile X-related protein and VIG associate with the RNA interference machinery. Genes. Dev., 16: 2491-2496. DOI: $10.1101 / \mathrm{gad} .1025202$

Ceribelli, A., B. Yao, P.R. Dominguez-Gutierrez, M.A. Nahid and M. Satoh et al., 2011. MicroRNAs in systemic rheumatic diseases. Arthritis Res. Ther., 13: 229-229. DOI: 10.1186/ar3377

Chan, J. A., A.M. Krichevsky and K.S. Kosik, 2005. MicroRNA-21 Is an antiapoptotic factor in human glioblastoma cells. Cancer Res., 65: 6029-6033. PMID: 16024602

Cheng, Y. and C. Zhang, 2010. MicroRNA-21 in cardiovascular disease. J. Cardiovasc. Transl. Res., 3: 251-255. DOI: 10.1007/s12265-010-9169-7

Cimmino, A., G.A. Calin, M. Fabbri, M. Shimizu and S.E. Wojcik et al., 2005. MiR-15 and miR-16 induce apoptosis by targeting BCL2. Proc. Natl. Acad. Sci. USA., 102: 13944-13949. DOI: 10.1073/pnas.0506654102

Costinean, S., S.K. Sandhu, I.M. Pedersen, E. Tili and R. Trotta et al., 2009. Src homology 2 domaincontaining inositol-5-phosphatase and CCAAT enhancer-binding protein $\beta$ are targeted by miR-155 in B cells of E $\mu-M i R-155$ transgenic mice. Blood, 114: 1374-1382. DOI: 10.1182/blood-2009-05220814

Croce, C.M., 2008. MicroRNAs and lymphomas. Ann. Oncol., 19: iv39-iv40. DOI: 10.1093/annonc/mdn192

Dalal, S.R. and J.H. Kwon, 2010. The role of MicroRNA in inflammatory bowel disease. Gastroenterol. Hepatol., 6: 714-722. PMID: 21437020

Dehwah, M.A.S., A. Xu and Q. Huang, 2012. microRNAs and type 2 diabetes/obesity. J. Genet Genomics, 39: 11-18. DOI: 10.1016/j.jgg.2011.11.007

D'Urso, P.I., O.F. D’Urso, C. Storelli, M. Mallardo and C.D. Gianfreda et al., 2012. MiR-155 is up-regulated in primary and secondary glioblastoma and promotes tumour growth by inhibiting GABA receptors. Int. J. Oncol., 228-234. DOI: 10.3892/ijo.2012.1420

Elton, T.S., M. Khan and D. Terentyev, 2011. MicroRNAs in cardiovascular disease. F1000 Med. Rep., 3: 10-10. DOI: 10.3410/M3-10
Esquela-Kerscher, A. and F.J. Slack, 2006. Oncomirs microRNAs with a role in cancer. Nat. Rev. Cancer., 6: 259-69. DOI: $10.1038 / \mathrm{nrc} 1840$

Fu, Y., Y. Zhang, Z. Wang, L. Wang and X. Wei et al., 2010. Regulation of NADPH oxidase activity is associated with miRNA-25-mediated NOX4 expression in experimental diabetic nephropathy. Am. J. Nephrol., 32: 581-589. DOI: 10.1159/000322105

Greither, T., L.F. Grochola, A. Udelnow, C. Lautenschlger and P. Wurl et al., 2010. Elevated expression of microRNAs 155, 203, 210 and 222 in pancreatic tumors is associated with poorer survival. Int. J. Cancer., 126: 73-80. DOI: 10.1002/ijc.24687

Griffiths-Jones, S., H.K. Saini, D.S. van and A.J. Enright, 2008. Mirbase: Tools for microRNA genomics. Nucl. Acids Res., 36: D154-D158. DOI: 10.1093/nar/gkm952

Hanlon, K., C.E. Rudin and L.W. Harries, 2009. Investigating the targets of MIR-15a and MIR-16-1 in patients with Chronic Lymphocytic Leukemia (CLL). PLoS One., 4: e7169. DOI: 10.1371/journal.pone.0007169

Hansen, T., L. Olsen, M. Lindow, K.D. Jakobsen and H. Ullum et al., 2007. Brain expressed microRNAs implicated in schizophrenia etiology. PLoS One., 2: e873-e873. DOI: 10.1371/journal.pone.0000873

Hassan, O., A. Ahmad, S. Sethi and F.H. Sarkar, 2012. Recent updates on the role of microRNAs in prostate cancer. J. Hematol. Oncol., 5: 9. DOI: 10.1186/17568722-5-9

Hebert, S.S., A.S. Papadopoulou, P. Smith, M.C. Galas and E. Planel et al., 2010. Genetic ablation of Dicer in adult forebrain neurons results in abnormal tau hyperphosphorylation and neurodegeneration. Hum. Mol. Genet., 19: 3959-3969. DOI: $10.1093 / \mathrm{hmg} / \mathrm{ddq} 311$

Hennessy, E., M. Clynes, P.B. Jeppesen, L. O’Driscollc, 2010. Identification of microRNAs with a role in glucose stimulated insulin secretion by expression profiling of MIN6 cells. Biochem. Biophys. Res. Commun., 396: 457-462. DOI: 10.1016/j.bbrc.2010.04.116

Jemal, A., F. Bray, M.M. Center, J. Ferlay and E. Ward et al., 2011. Global cancer statistics. CA: Cancer J. Clin., 61: 69-90. DOI: 10.3322/caac.20107

Joglekar, M.V., V.S. Parekh, S. Mehta, R.R. Bhondec and A.A. Hardikara, 2007. MicroRNA profiling of developing and regenerating pancreas reveal posttranscriptional regulation of neurogenin3. Dev. Biol., 311: 603-612. DOI: 10.1016/j.ydbio.2007.09.008 
Karolina, D.S., A. Armugam, S. Tavintharan, M.T. Wong and S.C. Lim et al., 2011. MicroRNA 144 impairs insulin signaling by inhibiting the expression of insulin receptor substrate 1 in type 2 diabetes mellitus. PLoS One, 6: e22839-e22839. PMID: 21829658

Kawano, S. and Y. Nakamachi, 2011. MiR-124a as a key regulator of proliferation and MCP-1 secretion in synoviocytes from patients with rheumatoid arthritis. Ann. Rheum. Dis., 70: i88-i91. DOI: 10.1136/ard.2010.138669

Kim, J., K. Inoue, J. Ishii, W.B. Vantil and S.V. Voronov et al., 2007. MicroRNA feedback circuit in midbrain dopamine neurons. Science, 317: 12201224. DOI: $10.1126 /$ science. 1140481

Krek, A., D. Grun, M.N. Poy, R. Wolf and L. Rosenberg et al., 2005. Combinatorial microRNA target predictions. Nat. Genet., 37: 495-500. DOI: $10.1038 /$ ng 1536

Kuehbacher, A., C. Urbich, A.M. Zeiher and S. Dimmeler, 2007. Role of Dicer and Drosha for endothelial microRNA expression and angiogenesis. Circ. Res., 101: 59-68. DOI: 10.1161/CIRCRESAHA.107.153916

Latronico, M., D. Catalucci and G. Condorelli, 2007. Emerging role of microRNAs in cardiovascular biology. Circ. Res., 101: 1225-1236. DOI: 10.1161/CIRCRESAHA.107.163147

Latronico, M.V.G. and G. Condorelli, 2009. MicroRNAs and cardiac pathology. Nat Rev Cardiol., 6: 418-429. DOI: $10.1038 /$ nrcardio.2009.56

Leng, R.X., H.F. Pan, W.Z. Qin, G.M Chen and D.Q. Ye, 2011. Role of microRNA-155 in autoimmunity. Cytokine Growth Factor Rev., 22: 141-147. DOI: 10.1016/j.cytogfr.2011.05.002

Lovis, P., S. Gattesco and R. Regazzi, 2008. Regulation of the expression of components of the exocytotic machinery of insulin-secreting cells by microRNAs. Biol. Chem., 389: 305-312. PMID: 18177263

Luo, X., B. Burwinkel, S. Tao and H. Brenner, 2011. MicroRNA signatures: Novel biomarker for colorectal cancer. Cancer Epidemiol. Biomarkers Prev., 7: 1272-1286. DOI: 10.1158/1055-9965.EPI11-0035

Maes, O.C., H.M. Chertkow, E. Wang, Eugenia and S.M. Hyman, 2009. MicroRNA: Implications for alzheimer disease and other human CNS disorders. Curr. Genomics, 10: 154-168. DOI: $10.2174 / 138920209788185252$
Moussay, E., K. Wang, J.H. Cho, K.V. Moera and S. Pierson et al., 2011. MicroRNA as biomarkers and regulators in B-cell chronic lymphocytic leukemia. Proc. Natl. Acad. Sci. USA., 108: 6573-6578. DOI: 10.1073/pnas.1019557108

Murakami, Y., M. Tanaka, H. Toyoda, K. Hayashi and M. Kuroda et al., 2010. Hepatic microRNA expression is associated with the response to interferon treatment of chronic hepatitis C. BMC Med. Genomics., 3: 48-48. DOI: 10.1186/17558794-3-48

Nagata, Y., T. Nakasa, Y. Mochizuki, M. Ishikawa and S. Miyak et al., 2009. Induction of apoptosis in the synovium of mice with autoantibody-mediated arthritis by the intraarticular injection of doublestranded MicroRNA-15a. Arthritis Rheum., 60: 2677-2683. DOI: 10.1002/art.24762

Nakasa, T., H. Shibuya, Y. Nagata, T. Niimoto and M. Ochi, 2011. The inhibitory effect of microRNA-146a expression on bone destruction in collagen-induced arthritis. Arthritis Rheum., 63: 1582-1590. DOI: 10.1002/art.30321

Odze, R., 2003. Diagnostic problems and advances in inflammatory bowel disease. Mod. Pathol., 6: 347358. PMID: 12692200

Pauley, K.M., M. Satoh, A.L. Chan, M.R. Bubb, W.H Reeves et al., 2008. Upregulated miR-146a expression in peripheral blood mononuclear cells from rheumatoid arthritis patients. Arthritis Res. Ther., 10: R101-R101. DOI: 10.1186/ar2493

Perkins, D.O., 2007. Neuroprotection: A new strategy in the treatment of schizophrenia. Early Detection and intervention. CNS Spectr., 12: 10-13. PMID: 19322959

Piepoli, A., F. Tavano, M. Copetti, T. Mazza and O. Palumbo et al., 2012. Mirna expression profiles identify drivers in colorectal and pancreatic cancers PLoS One, 7: e33663-e33663. DOI: 10.1371/journal.pone.0033663

Provost, P., 2010. MicroRNAs as a molecular basis for mental retardation, Alzheimer's and prion diseases. Brain Res., 18: 58-66. DOI: 10.1016/j.brainres.2010.03.069

Rink, C. and S. Khanna, 2011. MicroRNA in ischemic stroke etiology and pathology. Physiol. Genomics, 43: 521-528. PMID: 20841499

Roggli, E., A. Britan, S. Gattesco, N. Lin-Marq and A. Abderrahmani et al., 2010. Involvement of microRNAs in the cytotoxic effects exerted by proinflammatory cytokines on pancreatic $\beta$-cells. Diabetes, 59: 978-986. DOI: 10.2337/db09-0881 
Rooij, E.V. and E.N. Olson, 2007. MicroRNAs put their signatures on the heart. Physiol. Genomics, 31: 365366. DOI: 10.1152/physiolgenomics.00206.2007

Ryu, H.S., S.Y. Park, D. Ma, J. Zhang and W. Lee, 2011. The induction of microRNA targeting IRS-1 is involved in the development of insulin resistance under conditions of mitochondrial dysfunction in hepatocytes. PLoS One, 6: e17343-e17343. DOI: 10.1371/journal.pone.0017343

Schooneveld, E.V., M.C. Wouters, I.V.D. Auwera, D.J. Peeters and H. Wildiers et al., 2012. Expression profiling of cancerous and normal breast tissues identifies microRNAs that are differentially expressed in serum from patients with (metastatic) breast cancer and healthy volunteers. Breast Cancer Res., 4: R34-R34. DOI: 10.1186/bcr3127

Scott, G.K., A. Goga, D. Bhaumik, C.E. Berger and C.S. Sullivan et al., 2007. Coordinate suppression of ERBB2 and ERBB3 by enforced expression of micro-RNA miR-125a or miR-125b. Biol. Chem., 282: 1479-1486. DOI: 10.1074/jbc.M609383200

Shimono, Y., M. Zabala, R.W. Cho, N. Lobo and P. Dalerba et al., 2009. Downregulation of miRNA200c links breast cancer stem cells with normal stem cells. Cell, 138: 592-603. DOI: 10.1016/j.cell.2009.07.011

Si, M.L., S. Zhu, H. Wu, Z. Lu and F. Wu et al., 2007. miR-21-mediated tumor growth. Oncogene, 26: 2799-2803. DOI: 10.1038/sj.onc. 1210083

Sotiropoulou, G., G. Pampalakis, E. Lianidou and Z. Mourelatos, 2009. Emerging roles of microRNAs as molecular switches in the integrated circuit of the cancer cell. RNA, 15: 1443-1461. DOI: 10.1261/rna.1534709

Srivastava, S.K., A. Bhardwaj, S. Singh, S. Arora and B. Wang et al., 2011. MicroRNA-150 directly targets MUC4 and suppresses growth and malignant behavior of pancreatic cancer cells. Carcinogenesis, 12: 1832-1839. DOI: 10.1093/carcin/bgr223

Suarez, Y., C. Fernandez-Hernando, J. Yu, S.A. Gerber and K.D. Harrison et al., 2008. Dicer-dependent endothelial microRNAs are necessary for postnatal angiogenesis. Proc. Natl. Acad. Sci. USA., 37: 14082-14087. DOI: 10.1073/pnas.0804597105
Suarez, Y., C. Fernandez-Hernando, J.S. Pober and W.C. Sessa, 2007. Dicer dependent microRNAs regulate gene expression and functions in human endothelial cells. Circ. Res., 100: 1164-1173. DOI: 10.1161/01.RES.0000265065.26744.17

Takamizawa, J., H. Konishi, K. Yanagisawa, S. Tomida and H. Osada et al., 2004. Reduced expression of the let-7 microRNAs in human lung cancers in association with shortened postoperative survival. Cancer Res., 64: 3753-3756. PMID: 15172979

Takeshita, F., L. Patrawala, M. Osaki, R.U. Takahashi1 and Y. Yamamoto et al., 2010. Systemic delivery of synthetic microRNA-16 inhibits the growth of metastatic prostate tumors via downregulation of multiple cell-cycle genes. Mol. Ther., 18: 181-187. DOI: $10.1038 / \mathrm{mt} .2009 .207$

Tang, Y., J. Zheng, Y. Sun, Z. Wu and Z. Liu et al., 2009. MicroRNA-1 regulates cardiomyocyte apoptosis by targeting Bcl-2. Int. Heart J., 50: 377387. DOI: 10.1536/ihj.50.377

Te, J.L., I.M. Dozmorov, J.M. Guthridge, K.L. Nguyen and J.W. Cavett et al., 2010. Identification of unique microRNA signature associated with lupus nephritis. PLoS One, 11: e10344-e10344. DOI: 10.1371/journal.pone.0010344

Wang, Q., S. Wang, H. Wang, P. Li and Z. Ma, 2012. MicroRNAs: Novel biomarkers for lung cancer diagnosis, prediction and treatment. Exp. Biol. Med., 237: 227-235. DOI: 10.1258/ebm.2011.011192

Wittmann, J. and H.M. Jack, 2011. microRNAs in rheumatoid arthritis: Midget RNAs with a giant impact. Ann. Rheum. Dis., 70: i92-i96. DOI: 10.1136/ard.2010.140152

Wu, F., S. Zhang, T. Dassopoulos, M.L. Harris and T.M. Bayless et al., 2010. Identification of microRNAs associated with ileal and colonic Crohn's disease. Inflamm. Bowel. Dis., 6: 1729-1738. DOI: 10.1002/ibd.21267

Zhou, L., H. He, J.X. Mi, C. Li and B. Lee et al., 2008. MicroRNA genes. Ann. N. Y. Acad. Sci., 1150: 7275. DOI: $10.1196 /$ annals. 1447.026 